\title{
Up-Regulation Mttp and Apob Gene Expression in Rat Liver is Related to Post-Lipectomy Hypertriglyceridemia
}

\author{
Agnieszka Dettlaff-Pokora ${ }^{a}$ Tomasz Sledzinski ${ }^{b} \quad$ Julian Swierczynskia \\ aDepartment of Biochemistry, Medical University of Gdansk, Gdansk, bepartment of Pharmaceutical \\ Biochemistry, Medical University of Gdansk, Gdansk, Poland
}

\author{
Key Words \\ TAG $・ H N F 1 \alpha \cdot H N F 4 \alpha \cdot F A S N \cdot$ DGAT $・$ SREBP-1 $\bullet$ S14 $\bullet$ Lipectomy
}

\begin{abstract}
Background/Aims: The aim of this study was to explain the molecular basis for elevated concentrations of circulating triglycerides (TAGs) after partial surgical removal of adipose tissue (lipectomy) in rats. Methods: The levels of mRNA and protein: a) involved in synthesis of fatty acids and TAGs; b) participating in TAG-rich lipoproteins assembly and secretion; and c) transcription factors essential for maintaining TAG homeostasis were determined by RTPCR and Western Blot in the livers of control and lipectomized rats. Results: Partial lipectomy was associated with increase: a) in serum and liver concentration of TAGs, and b) in the liver levels of mRNA of microsomal TAG transfer protein (MTP) and apolipoprotein B-100 (ApoB100). These changes were tightly associated with up-regulation of Hnfla and Hnf4a gene expression in the liver. Lipectomy was also reflected by a significant increase in the expression of genes encoding: a) fatty acid synthase (FASN), b) glycerol 3-phosphate acyltransferase 1 (GPAT1), diacylglycerol acyltransferases 1 and 2 (DGAT1 and DGAT2), c) spot 14 protein (S14) and SREBP-1 in the liver. Conclusion: Coordinated up-regulation of Mttp, Apob, Hnfla, Hnf4a, Fasn, Gpam and Dgat (1 and 2) gene expressions may contribute to the increase in circulating and liver concentrations of TAGs after lipectomy in an experimental rat model.
\end{abstract}

Copyright (C) 2015 S. Karger AG, Basel

\section{Introduction}

Liposuction is one of the most popular esthetic surgeries worldwide, recommended by the American Academy of Cosmetic Surgery [1]. However, health consequences of Julian Swierczynski 
liposuction are still poorly understood. Moreover, the results of previous studies dealing with the problem in question are inconclusive [2-6]. Nevertheless, some authors showed that liposuction is safe and beneficial procedure resulting in an amelioration of insulin resistance and decrease in the markers of vascular inflammation [2-5].

The reports on changes in serum triglyceride (TAG) concentration following lipectomy in humans are also inconclusive. While some authors showed that liposuction exerts no effect on serum TAG concentration in humans $[3,6]$, others demonstrated that this procedure is reflected by a decrease in this parameter [7]. Furthermore, some studies documented a post-liposuction increase in serum TAG concentration [8]. Since an increase in serum TAG concentration was shown to be associated with elevated risk of myocardial infarction, ischemic stroke, preterm death [9-11] and acute pancreatitis [12], the post-lipectomy changes in serum TAG concentration require further study.

Recently, Ling et al. [13] reported that lipectomy results in an increase in serum TAG concentration and up-regulation of liver genes encoding proteins involved in lipid metabolism in rats. They suggested that lower serum concentration of adiponectin may contribute to the post-lipectomy hyperlipidemia [13]. Interestingly, elevated level of serum TAGs was also reported in transgenic mice (A-ZIP/F-1 mice) lacking white adipose tissue (WAT) [14]. These results suggest that limited amount of adipose tissue (as is the case after lipectomy) and/or complete lack thereof (as in transgenic mice) may be associated with hypertriglyceridemia.

Theoretically, the post-lipectomy increase in serum TAGs may result from their enhanced liver synthesis, as well as from the production and release of very low density lipoproteins (VLDL). The synthesis and secretion of TAGs in the liver are dependent on the coordinated function of several genes, including two playing a dominant role in these processes. These are Mttp and Apob genes, encoding microsomal triglyceride transfer protein (MTP) and apolipoprotein B-100 (ApoB-100), respectively. MTP and ApoB-100 play a key role in the assembly and secretion of TAG-rich ApoB-containing lipoproteins, such as VLDL [15-22]. Aside from MTP and ApoB-100, also hepatocyte nuclear factor $4 \alpha$ (HNF4 $\alpha$ ), being essential for maintaining TAG homeostasis [23-25], and diacylglycerol acyltransferases 1 and 2 (DGAT1 and DGAT2), i.e. enzymes participating in TAG synthesis, are also involved in the regulation of the TAG-rich lipoproteins secretion [26, 27]. Moreover, the liver biosynthesis of TAGs is enhanced due to increased availability of fatty acids synthesized from glucose in hepatocytes [22]. Also the assembly of VLDL was shown to be dependent on both the fatty acid production and the subsequent biosynthesis of TAGs [22].

To explain potential mechanism(s) leading to the post-lipectomy increase in serum TAG concentration, we examined the expression of genes encoding: a) proteins involved in the synthesis of fatty acids (fatty acid synthase, FASN) and TAGs (glycerol 3-phosphate acyltransferase, GPAT1, DGAT1 and DGAT2), b) proteins participating in the TAG-rich lipoproteins assembly and secretion (MTP and ApoB-100), and c) proteins essential for maintaining TAG homeostasis (HNF4 $\alpha, \mathrm{HNF} 1 \alpha)$ in control and lipectomized rats.

\section{Materials and Methods}

\section{Animals and surgeries}

The rats fed commercial diet, composition of which has been described previously [28], were treated as described recently [29]. Briefly, 12-week-old male Wistar rats were randomly divided into two groups: 1) lipectomized rats $(\mathrm{n}=10)$ subjected to resection of epididymal and retroperitoneal WAT, and 2) controls $(n=10)$ that underwent anesthesia and incision of the skin and muscles without the removal of WAT (sham surgery). After 30 days, the lipectomized rats were anesthetized again with subsequent removal of subcutaneous WAT, and the controls were subjected to another sham surgery. Mean weight of WAT removed from the lipectomized rats was $7.7 \pm 0.6 \mathrm{~g}(3.8 \pm 0.3 \mathrm{~g}, 2.0 \pm 0.4 \mathrm{~g}$ and $1.9 \pm 0.4 \mathrm{~g}$ for subcutaneous, epididymal and retroperitoneal WAT, respectively). The lipectomy was performed as the two-step procedure in order to reduce perioperative mortality. The surgeries were conducted carefully to avoid bleeding. All the procedures involving animals and their care were approved by the Institutional 
Ethics Committee. The rats were anesthetized and killed by decapitation (between 8:00 a.m. and 10:00 a.m.) after 90 days from the first surgery. Blood samples from the carotid artery were collected to the tubes without anticoagulant, centrifuged at $3000 \times \mathrm{g}$ for $15 \mathrm{~min}$ at $4^{\circ} \mathrm{C}$, and the serum was stored at $-20^{\circ} \mathrm{C}$. The liver fragments were obtained, immediately frozen in liquid nitrogen and stored at ${ }^{-8} 80^{\circ} \mathrm{C}$ until analysis. Epididymal, retroperitoneal and subcutaneous WAT from the controls, as well as the residual WAT from the lipectomized animals, were removed and weighted.

\section{RNA isolation and $m R N A$ level determination}

Total cellular RNA was isolated from the frozen liver samples with a commercial RNA isolation kit (Total RNA Mini, A\&A biotechnology, Poland). RNA concentration was determined on the basis of absorbance at $260 \mathrm{~nm}$; all the samples showed $260 / 280 \mathrm{~nm}$ absorbance ratio of about 2.0. Prior to the reverse transcription, the RNA samples were treated with RNase-free DNase I (Fermentas, International Inc., Canada). First strand cDNA synthesis and the determination of mRNA levels by RT-PCR were performed as described previously [29], using a Chromo4 Real-Time Detection System (Bio-Rad Laboratories Inc., USA). The primer sequences used in this study are presented in Table 1. $\beta$-actin mRNA was used as an internal standard. Relative quantities of the transcripts were calculated using the $2^{-\Delta \Delta C T}$ formula [30]. The amplification of specific transcripts was further confirmed on the basis of the melting curve profiles.

Determination of liver TAGs

Liver lipids were extracted with Folch method [31] and concentration of TAGs was determined by means of Oil Red 0 spectroscopic assessment [32] with triolein as a standard.

Determination of serum TAGs

Serum TAG concentration was determined using a routine method, at the Central Clinical Laboratory, Medical University of Gdansk.

Fatty acid synthase activity assay

$0.2 \mathrm{~g}$ of liver tissue was homogenized in $1.8 \mathrm{ml}$ of ice-cold buffer $(25 \mathrm{mM}$ Tris- $\mathrm{HCl} \mathrm{pH} \mathrm{7.8,} \mathrm{0.2 \%} \mathrm{Triton}$ $\mathrm{X}$-100). The homogenate was centrifuged at $30000 \times \mathrm{g}$ for $20 \mathrm{~min}$ at $4^{\circ} \mathrm{C}$. The activity of fatty acid synthase (FASN; EC 2.3.1.85) in the supernatant was measured spectrophotometrically as described elsewhere [33], with a Beckman DU 68 spectrophotometer (Beckman Instruments, Fullerton, USA).

\section{SDS-PAGE and immunoblotting}

Frozen rat liver was homogenized in $20 \mathrm{mM}$ Tris-HCl buffer (pH 7.8) containing $0.2 \%$ Triton $\mathrm{X}-100$ and protease inhibitor cocktail (Sigma, USA), and then centrifuged. Aliquots of the obtained supernatants containing $10 \mu \mathrm{g}$ of protein were separated by $10 \%$ SDS-PAGE and electroblotted to Immuno-Blot ${ }^{\mathrm{TM}}$ PVDF Membrane (Bio-Rad Laboratories, Hercules CA, USA). The membrane was blocked by incubation with blocking buffer, and then incubated with rabbit polyclonal antiHNF4 $\alpha$ antibody (NBP1-00876, Novusbio), mouse monoclonal anti-HNF1 $\alpha$ antibody (GTX12064, GeneTex), mouse monoclonal anti-MTP antibody (sc-135994, Santa Cruz, CA, USA), rabbit polyclonal anti-ApoB-100 antibody (sc-25542, Santa Cruz, CA, USA), mouse monoclonal anti-FASN antibody (sc55580, Santa Cruz, CA, USA), and rabbit polyclonal anti-actin antibody (A 5060, Sigma-Aldrich). Secondary HRP-conjugated antibodies were obtained from Sigma Aldrich (A0545, A9044). The reactions were visualized with a SuperSignal West
Table 1. Primer sequences used in the study

\begin{tabular}{ll}
\hline Gene & Primer sequence (5'-3') \\
\hline Hnf1 $\alpha$ & F: AAGATGACACGGATGACGATGG \\
& R: GGTTGAGACCCGTAGTGTCC \\
Hnf4a & F: AAATGTGCAGGTGTTGACCA \\
& R: CACGCTCCTCCTGAAGAATC \\
Thrsp & F: GGTACTCGGCTGTGGTGCGG \\
& R: AGATCGGGGGCTCCGTCCTG \\
Srebf1 & F: TCAGTTCCAGCATGGCTACC \\
& R: TGGGGAATGTGCTCTACCAG \\
Dgat1 & F: TGGGTTCCCTGTTTGCTCTGGC \\
& R: GCTTTGGCCTTGACCCTTCGCT \\
Dgat2 & F:GGGTCCTATCCTTCCTGGTG \\
& R:ACCTTTCTTGGGCGTGTTC \\
Fasn & F: ATGGGAAGGTGTCTGTGCACAT \\
& R: TGTGGATGATGTTGATGATA \\
Gpam & F: TCTGCCGCTCTTGTTTCTGCCG \\
& R: GGATGTTGAGGTTGTTGCCCGA \\
Mttp & F: AAGGCCAATATGGACATCCAGGGT \\
& R: TGGTTATTACCACAGCCACCCGAT \\
Apob & F: AGTCTACTGGAAGCCATGAAGGG \\
Actb & R: AATCTGCTGAGGAAGCCTGCTCA \\
& F: GAAATCGTGCGTGACATTAAG \\
& R: GCTAGAAGCATTTGCGGTGGA \\
\hline
\end{tabular}


Pico chemiluminescent substrate (Thermo Fisher Scientific Inc., Rockford, IL, USA). The bands (visible on the film after the chemiluminescent detection) were compared to molecular mass protein markers (SM1811) obtained from Fermentas, visible on the membrane after electroblotting. The film was adjusted to the membrane in such way that the membrane edges were visible on the film.

\section{Statistical analysis}

Statistical analysis was conducted using a MS Excel 2010 spreadsheet (Microsoft). All the data were expressed as mean values $( \pm$ SD) for the controls and lipectomized rats. The significance of intergroup differences in the analyzed parameters was verified with Student t-test. The differences were considered significant at p-value $<0.05$.

\section{Results}

The effects of lipectomy on the mass of subcutaneous (inguinal), retroperitoneal and epididymal WAT were recently reported [29]. Briefly, lipectomy resulted in a complete reduction of subcutaneous adipose tissue and approximately $80 \%$ reduction of retroperitoneal and epididymal adipose tissue as compared to the control rats. Consequently, the overall reduction of subcutaneous, retroperitoneal and epididymal adipose tissue mass in the lipectomized rats corresponded to approximately $90 \%$. Mean baseline body weights of the controls and lipectomized rats were essentially similar ( $312 \pm 18 \mathrm{~g}$ vs. $315 \pm 19 \mathrm{~g}$ ). Mean final body weights determined at the end of the experiment were $403 \pm 21 \mathrm{~g}$ and $407 \pm 17 \mathrm{~g}$ for the controls and lipectomized rats, respectively.

Partial lipectomy was reflected by approximately 2 -fold increase in the serum concentration of TAGs (Fig. 1A), as well as by an increase in the liver TAG content (Fig. 1B). Moreover, higher levels of MTP mRNA were also found in the livers of lipectomized rats (Fig. 2A). The different liver levels of MTP mRNA observed in the controls and lipectomized rats were reflected by intergroup differences in the liver levels of MTP protein documented on Western Blot analysis (Fig. 5). Presumably, enhanced expression of Mttp gene contributed to the increase in the serum and liver TAG concentrations in the lipectomized rats (Fig. 1A and 1B). This assumption was supported by a strong positive correlation found between the liver MTP mRNA level and the serum concentration of TAGs $(r=0.67, p<0.05)$. Partial lipectomy was also associated with approximately 2-fold increase in the liver level of ApoB-100 mRNA (Fig. 2B). Moreover, we found a strong positive correlation between the liver level of ApoB100 mRNA and the serum concentration of TAGs $(r=0.82, p<0.05)$. The different liver levels of ApoB-100 mRNA in the controls and lipectomized rats were reflected by intergroup differences in the liver concentrations of Apo-B100 protein documented on Western Blot analysis (Fig. 5).

Fig. 1. Triglyceride levels in: A) serum and B) liver of the controls and lipectomized rats. Data presented as mean \pm SD. $* \mathrm{p}<0.05$.

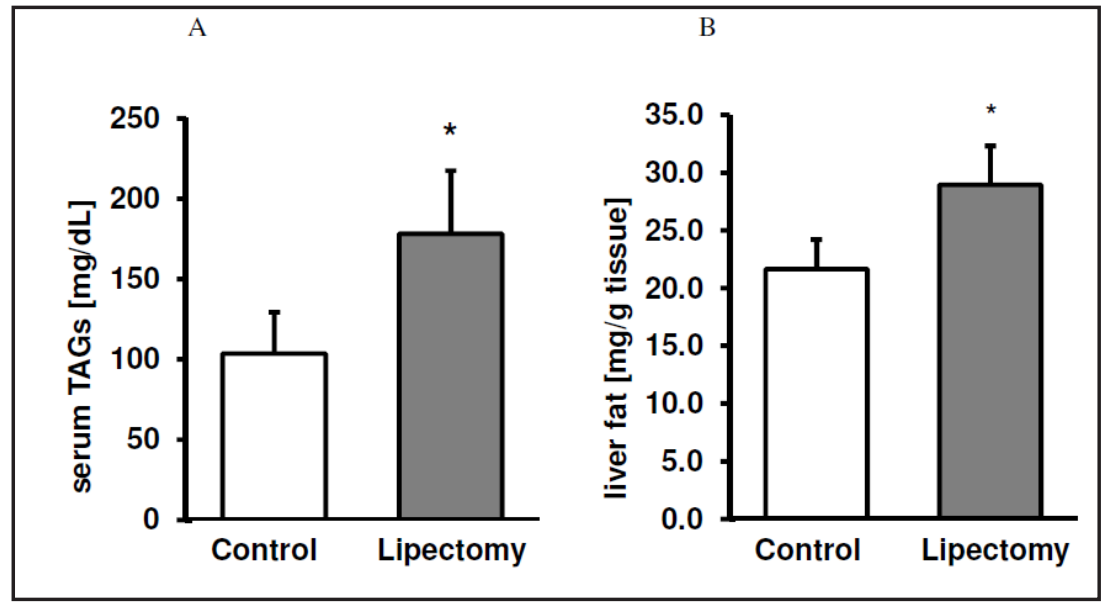


Fig. 2. The mean A) microsomal TAG transfer protein (MTP) and B) Apolipoprotein B-100 (ApoB-100) relative mRNA levels in the livers of the controls and lipectomized rats. Data presented as mean \pm SD. $* \mathrm{p}<0.05$. hepatocyte nuclear factor $1 \alpha(\mathrm{HNF} 1 \alpha)$ and B) hepatocyte nuclear factor $4 \alpha \quad$ (HNF4 $\alpha)$ relative mRNA levels in the livers of the controls and lipectomized rats. Data presented as mean \pm SD. * $\mathrm{p}<0.05$.
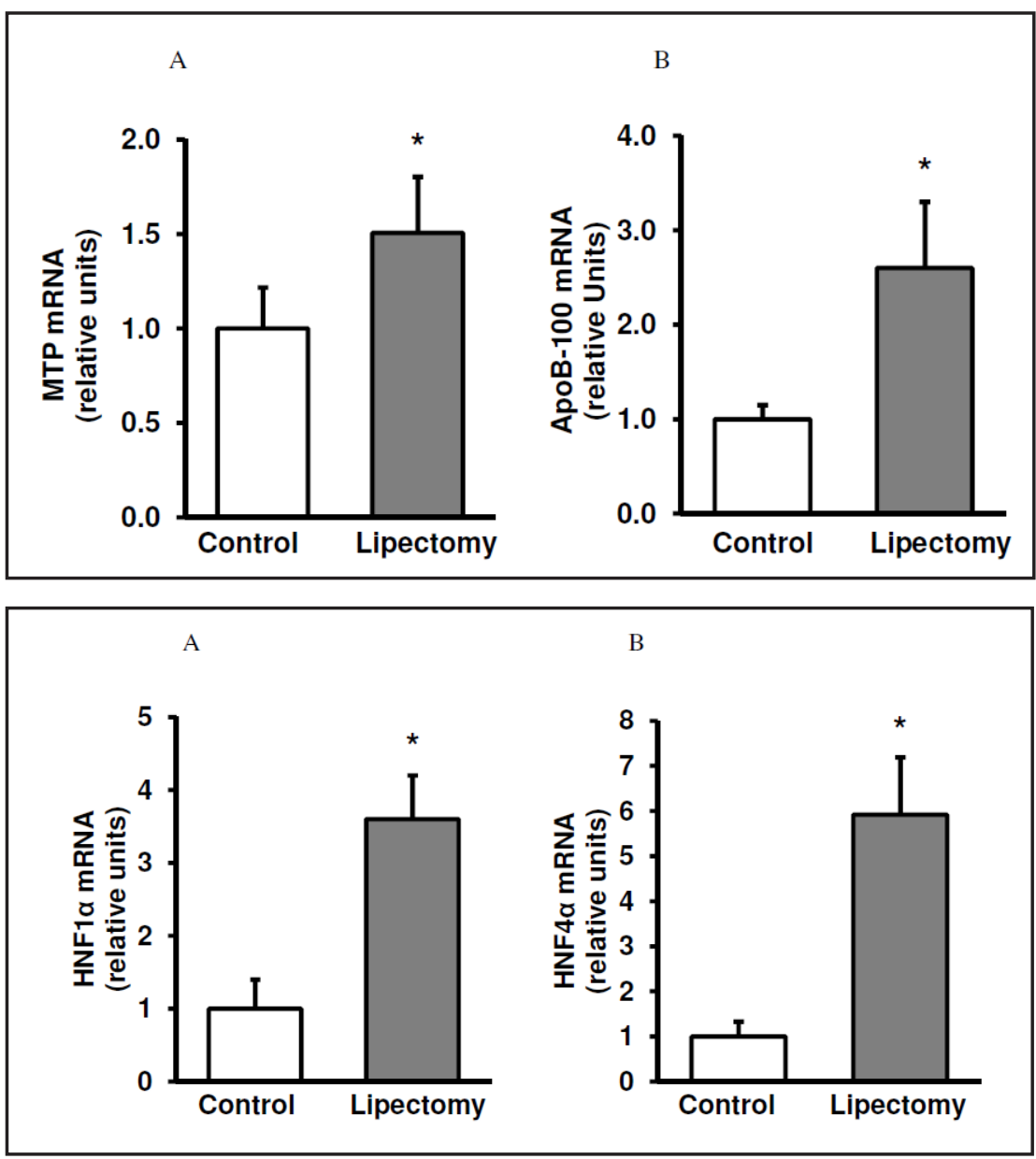

Partial lipectomy was reflected by a significant increase in the liver HNF1 $\alpha$ (Fig. 3A) and HNF4 $\alpha$ (Fig. 3B) mRNA levels. Interestingly, the pattern of changes in the liver HNF1 $\alpha$ and HNF4 $\alpha$ mRNA levels of the controls and lipectomized rats resembled that observed in the case of MTP and ApoB-100 mRNA levels (Fig. 2A and 2B, respectively). The different liver levels of HNF $1 \alpha$ and HNF $4 \alpha$ mRNA of the controls and lipectomized rats were reflected by intergroup differences in the HNF1 $\alpha$ and HNF4 $\alpha$ protein levels documented on Western Blot analysis (Fig. 5). Moreover, strong positive correlations were found between the liver levels of MTP mRNA and HNF1 $\alpha$ mRNA $(r=0.85, p<0.05)$, as well as between the levels of MTP mRNA and HNF4 $\alpha$ mRNA ( $r=0.83, p<0.05)$. We also found positive correlations between the liver levels of ApoB mRNA and HNF1 $\alpha$ mRNA ( $r=0.81, p<0.05)$, as well as between the levels of ApoB mRNA and HNF4 $\alpha$ mRNA ( $r=0.88$; $p<0.05$ ).

Partial lipectomy was associated with a significant increase in the liver activity of FASN (lipectomy: $1.74 \pm 0.38$; controls: $1.16 \pm 0.2 \mathrm{nmol} / \mathrm{min} / \mathrm{mg}$ protein), as well as by an increase in FASN mRNA (Fig. 4A) and FASN protein levels (Fig. 5). Importantly, the pattern of changes in the liver levels of FASN mRNA of the controls and lipectomized rats resembled that observed in the case of HNF1 $\alpha$ mRNA levels. The livers of the lipectomized rats contained more SREBP-1 mRNA than the control livers (Fig. 4B). Moreover, we observed an up-regulation of Thrsp gene (Fig. 4C) in the livers of the lipectomized rats. This gene encodes S14 (spot 14 protein) being critical for the activation of lipogenic enzymes, synthesis of lipids and export of VLDL $[34,35]$. Furthermore, lipectomy resulted in an increase in the mRNA levels for glycerol 3-phosphate acyltransferase 1 (GPAT1) (Fig 4D), an enzyme involved in the initial step of the liver biosynthesis of glycerolipids (including TAG) [36], as well as in an increase in the mRNA levels of diacylglycerol acyltransferases 1 and 2 (DGAT1 and DGAT2) (Fig. 4E, $4 \mathrm{~F}$ ), being involved in the final step of TAG biosynthesis in the liver and other tissues [37].

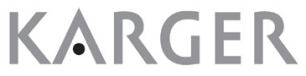


A

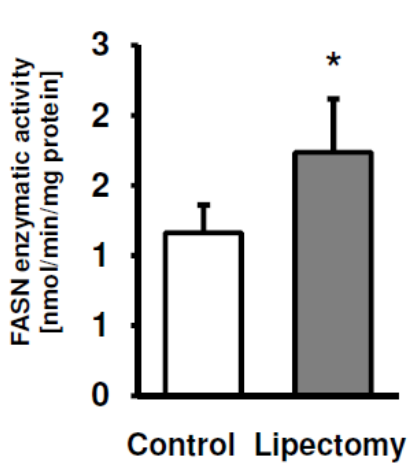

B

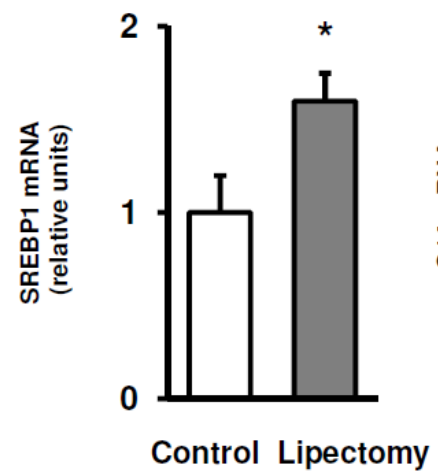

$\mathrm{C}$

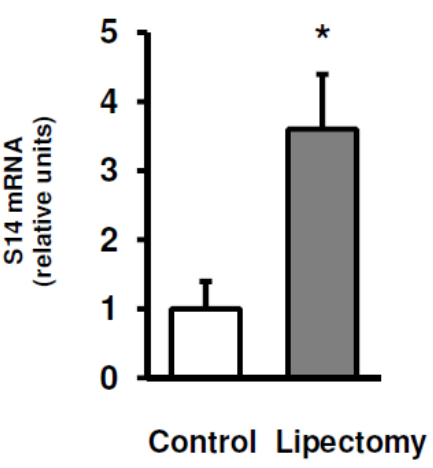

D

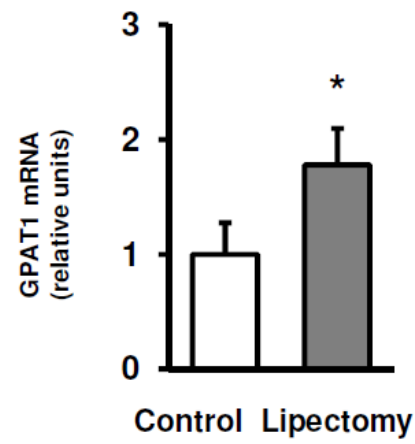

$E$

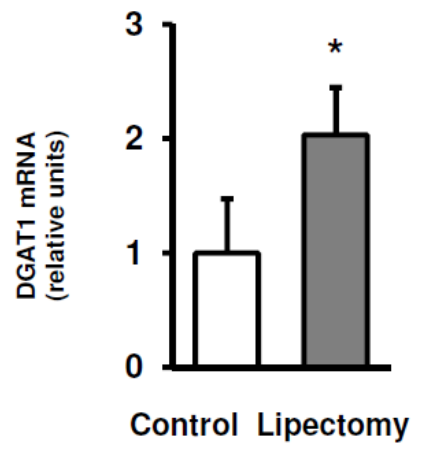

$\mathrm{F}$

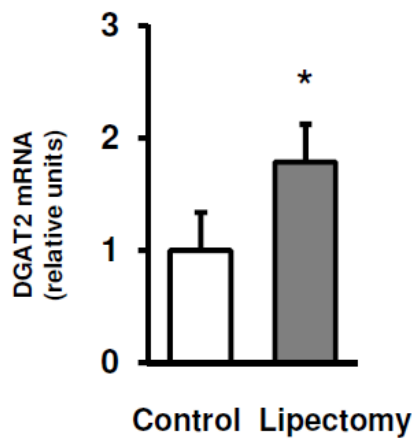

Fig. 4. The mean A) fatty acid synthase (FASN), B) sterol regulatory element binding protein 1 (SREBP-1), C) Spot 14 protein (S14), D) glycerol 3-phosphate acyltransferase 1 (GPAT1), E) diacylglycerol acyltransferases 1 (DGAT1) and F) diacylglycerol acyltransferases 2 (DGAT2) relative mRNA levels in the livers of the controls and lipectomized rats. Data presented as mean \pm SD. ${ }^{*} \mathrm{p}<0.05$.

\section{Discussion}

To the best of our knowledge, this study was the first to show that the surgical removal of adipose tissue may be associated with coordinated up-regulation of Mttp and Apob genes in the liver. These changes were associated with the increase in the serum and liver concentrations of TAGs. This suggests that the up-regulation of proteins involved in the assembly and secretion of TAG-rich lipoproteins may contribute to an increase in the serum concentration of TAGs after lipectomy. Taking into account the results of previous studies in which HNF1 $\alpha$ and HNF4 $\alpha$ were shown to be transcriptional activators of Mttp and Apob genes [38,39], and our hereby presented findings, we postulate that these hepatocyte nuclear factors (HNFs) might contribute to the hypertriglyceridemia observed in lipectomized rats. This is consistent with the results of a recent study in which lipectomized rats presented with higher concentrations of circulating TAGs and higher liver levels of HNF4 $\alpha$ mRNA than the sham-operated controls [13]. Further evidence supporting a role of HNFs in the post-lipectomy increase in serum TAGs comes from a study of Mttp and Apob expressions and serum TAG concentrations in mice lacking liver $H n f 4 a$; these animals presented with significantly lower serum concentrations of TAGs [40]. Furthermore, Yin et al. [41] observed a significant decrease in the liver expressions of Mttp and Apob as well as an impairment of 
Fig. 5. Western Blot analysis of liver MTP, HNF1, HNF4, FASN, ApoB100 standardized against actin in the controls and lipectomized rats.

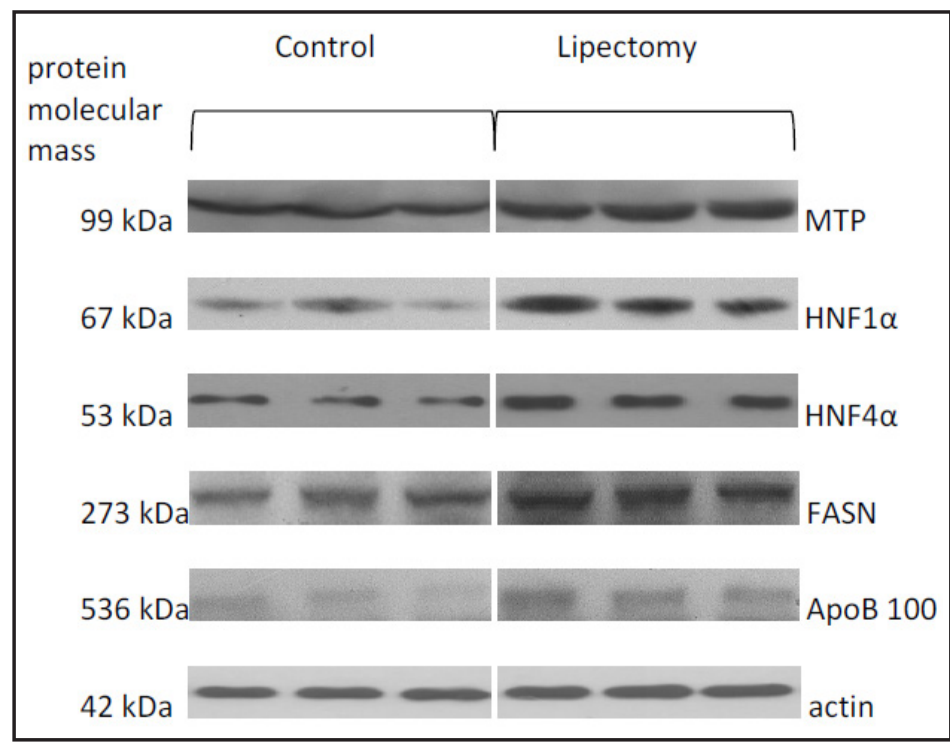

Fig. 6. Proposed mechanism showing how HNFs may affect circulating TAG concentrations in lipectomy rats. Lipectomy is associated with increase in $\operatorname{Hnf} 4 \alpha$ and $\operatorname{Hnf} 1 \alpha$ genes expression and consequently with increase in HNF1 $\alpha$ and HNF4 $\alpha$ protein levels. In turn, HNF1 $\alpha$ upregulates Mttp and ApoB genes expression, products of which increase the VLDL production and secretion. HNF1 $\alpha$ increases SREBP-1 production, which upregulates genes encoding enzymes involved in fatty acids and TAG synthesis. Moreover, HNF1 $\alpha$ might directly increase the expression of Fasn, and subsequently FASN level. For details see Discussion.

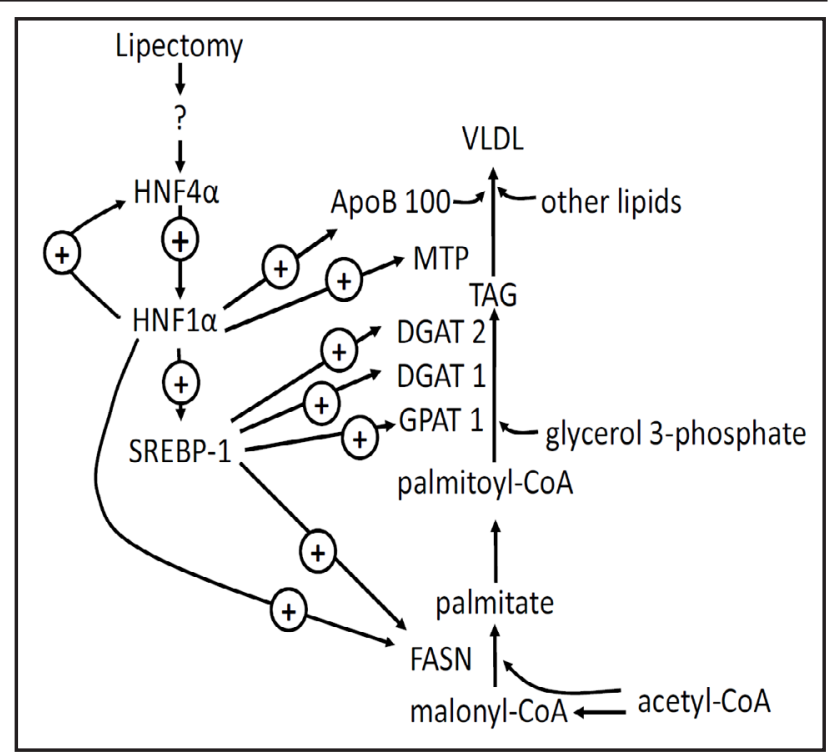

VLDL secretion in Hnf4a deficient mice. Taken together, the results of previous studies and our findings suggest that HNFs may significantly affect metabolism of lipids in rats subjected to surgical removal of adipose tissue. However, the reasons behind the increase in the liver expressions of Hnf1a and Hnf4a after surgical removal of adipose tissue are still unclear. The expression of Hnf4a was postulated to be down-regulated by cytokines [42], and removal of adipose tissue was shown to be reflected by a decrease in the circulating levels of proinflammatory cytokines $[43,44]$. Thus, it can be hypothesized that surgical removal of adipose tissue in rats may result in a decrease in cytokine levels, which in turn enhances the expression of $H n f 4 a$ gene.

It has been suggested that the expression Hnf1a is regulated by HNF4 $\alpha$ which binds to a specific nucleotide sequence present in the promoter of this gene [45]. Thus, HNF4 $\alpha$ may enhance the expression of Hnf1a in the livers of lipectomized rats and play crucial role as a regulator of Mttp and Apob genes. While several authors postulated that HNF4 $\alpha$ is an upstream transcription factor of HNF1 $\alpha$, some researchers suggest that it is rather HNF1 $\alpha$ which regulates the expression of $\operatorname{Hnf} 4 a[45,46]$. Nevertheless, the reciprocal relationship between HNF1 $\alpha$ and HNF4 $\alpha$ may play a role in the control of genes encoding proteins involved in the assembly and secretion of VLDL.

\section{KARGER}


As mentioned above, aside from MTP and ApoB-100, also DGAT1 [26] and DGAT2 [27] are involved in the regulation of TAG-rich lipoprotein secretion. Moreover, DGAT1 was shown to contribute to the effect of HNF $4 \alpha$ on the liver secretion of TAG-rich protein in human hepatoma cells [24]. Our findings suggest that both DGAT1 and DGAT2 were up-regulated in the livers of lipectomized rats (Fig. 4). Moreover, the overexpression of DGAT1 and DGAT2 turned out to be associated with the increase in the liver levels of HNFs in our lipectomized rats (Fig. 3 and 4). These observations are consistent with the results of previous studies dealing with the problem in question [42]. Therefore, the up-regulation of HNFs likely results in an up-regulation of several other proteins, such as MTP, ApoB-100 and DGAT (1 and 2) which play a crucial role in the assembly and secretion of VLDL, thus leading to hypertriglyceridemia in lipectomized rats.

Liver biosynthesis of TAGs is enhanced due to increased availability of fatty acids synthesized from glucose in hepatocytes [47]. Also the assembly of VLDL and resultant production of TAGs are known to be fatty acid-dependent [22]. Previous studies showed that fatty acid synthase (FASN), an enzyme involved in the synthesis of fatty acids being essential for TAG production, also is a down-stream target for HNF1 $\alpha$ [48]. Thus, the upregulation of Hnf1a is likely associated with the enhancement of Fasn expression in the livers of lipectomized rats. The data presented on Figure 4 suggests that this was the case in our lipectomized animals. Moreover, HNF1 $\alpha$ is also involved in the regulation of Srebf gene [48], and the product of this gene (SREBP-1) is a key regulator of lipogenesis [49]. Therefore, the up-regulation of Hnf1a is likely associated with the enhancement of Srebf gene expression in the livers of lipectomized rats. This may explain why our lipectomized rats presented with higher liver levels of SREBP-1 mRNA than the controls (Fig. 4). To summarize, up-regulation of both Hnfs and Srebf may contribute to the enhancement of Fasn expression and resultant increase in the lipogenic activity.

Based on the data reported previously, indicating that Mttp, ApoB, Fasn and Srebf-1 are target genes for HNFs $[38,39,48]$ and the results presented in this paper, we propose a mechanistic scheme showing how HNFs may affect circulating TAG concentrations in lipectomy rats (Fig. 6). For reasons which are not entirely clear, but could be related to lipectomy, the increase of $H n f 4 \alpha$ and $H n f 1 \alpha$ genes expression, and subsequently the HNF $1 \alpha$ and HNF $4 \alpha$ accumulation occur. In turn, HNF1 $\alpha$ through binding to mttp and apoB promoters could play a crucial role in controlling $m t t p$ and $a p o B$ genes expression, products of which govern the VLDL production and secretion. HNF1 $\alpha$ through binding to Srebf-1 promoter increases SREBP-1 production, which regulates genes encoding enzymes involved in fatty acids and TAG synthesis. Moreover, HNF1 $\alpha$ through binding to Fasn promoter may directly (not involving SREBP-1) increase FASN level. Overall, hypertriglyceridemia is likely accompanied by overproduction of proteins involved in: a) fatty acid and TAG synthesis, and b) assembly and secretion of VLDL. Since HNF1 $\alpha$ is an upstream transcription factor for proteins involved in fatty acid and TAG synthesis and proteins participating in assembly and secretion of VLDL, it could be considered as a master regulator of TAG synthesis, and subsequently circulating TAG concentrations in lipectomy rats.

In view of the important role of HNF1 $\alpha$ and HNF4 $\alpha$ in the lipid metabolism and maintenance of serum TAG concentration in lipectomized rats, one may ask how these findings translate onto humans subjected to liposuction. Taking into account the results of previous studies, namely the fact that: a) serum TAG concentrations were shown to be significantly reduced in $\mathrm{HNF} 4 \alpha$ mutation carriers $\left(\mathrm{HNF}^{+/}\right.$- patients with maturity-onset diabetes of the young, MODY1) [50], and b) a significant association was observed between the liver HNF4 and DGAT1 mRNA levels, as well as between DGAT1 mRNA and plasma concentrations of TAGs in humans [42], we hypothesize that similar to the lipectomized rats, patients after liposuction may present with increased liver levels of HNF1 $\alpha$ and HNF4 $\alpha$, and resultant enhancement of Mttp and Apob expressions. Ybarra et al. [51] showed that liposuction of subcutaneous abdominal fat in overweight subjects results in an increase in circulating ApoB-100. This observation is in line with our hereby presented findings. However, contrary to other studies [8], these authors [51] observed a post-liposuction 
decrease in the serum concentrations of TAGs. Thus, it would be inappropriate to speculate if the changes taking place in humans subjected to liposuction are similar to those observed in our partially lipectomized rats.

In conclusion, our study showed that partial surgical removal of WAT in rats is associated with the coordinated up-regulation of $H n f 1 a, H n f 4 a$ and genes encoding proteins involved in the synthesis, assembly and secretion of TAG-rich proteins. Consequently, the post-lipectomy increase in serum TAG concentration may result from enhanced synthesis and secretion of TAGs in the liver. Although our findings provide a new insight into postlipectomy metabolism of lipids, further studies are necessary to determine an association between hypertriglyceridemia and up-regulation of Mttp, Apob, Hnfla and Hnf4a in humans subjected to liposuction.

\section{Acknowledgements}

This work is dedicated to Professor Mariusz M. Zydowo on his $90^{\text {th }}$ birthday. The study was supported from the Medical University of Gdansk grants no. ST-41 and ST-40 and by Ministry of Science and Higher Education of the Republic of Poland, from the quality promoting subsidy, under the Leading National Research Centre (KNOW) programme for the years $2012-2017$.

\section{Disclosure Statement}

We have no conflict of interest to disclose.

\section{References}

1 American Academy of Cosmetic Surgery (AACS): 2006 Guidelines for Liposuction Surgery. In: 2006: A joint Ad Hoc Committee of the American Society of Lipo-Suction Surgery (ASLSS) and the American Academy of Cosmetic Surgery 2006. http://cosmeticsurgery.org/doctors/2006_liposuction_guidelines.pdf. (Accessed June 2012)

-2 Danilla S, Longton C, Valenzuela K, Cavada G, Norambuena H, Tabilo C, Erazo C, Benitez S, Sepulveda S, Schulz R, Andrades P: Suction-assisted lipectomy fails to improve cardiovascular metabolic markers of disease: a meta-analysis. J Plast Reconstr Aesthet Surg 2013;66:1557-1563.

- Klein S, Fontana L, Young VL, Coggan AR, Kilo C, Patterson BW, Mohammed BS: Absence of an effect of liposuction on insulin action and risk factors for coronary heart disease. N Engl J Med 2004;350:25492557.

-4 Martinez-Abundis E, Molina-Villa CA, Gonzalez-Ortiz M, Robles-Cervantes JA, Saucedo-Ortiz JA: Effect of surgically removing subcutaneous fat by abdominoplasty on leptin concentrations and insulin sensitivity. Ann Plast Surg 2007;58:416-419.

5 Giugliano G, Nicoletti G, Grella E, Giugliano F, Esposito K, Scuderi N, D'Andrea F: Effect of liposuction on insulin resistance and vascular inflammatory markers in obese women. Br J Plast Surg 2004;57:190-194.

6 Mohammed BS, Cohen S, Reeds D, Young VL, Klein S: Long-term effects of large-volume liposuction on metabolic risk factors for coronary heart disease. Obesity (Silver Spring) 2008;16:2648-2651.

7 Swanson E: Prospective clinical study reveals significant reduction in triglyceride level and white blood cell count after liposuction and abdominoplasty and no change in cholesterol levels. Plast Reconstr Surg 2011;128:182e-197e.

8 Robles-Cervantes JA, Castillo-Salcedo T, Guerrerosantos J, Gonzalez-Ortiz M, Martinez-Abundis E, LlamasMoreno JF, Ramos-Zavala MG, Gallegos-Arreola MP: Behavior of visfatin in nonobese women undergoing liposuction: a pilot study. Aesthet Surg J 2010;30:730-732.

-9 Nordestgaard BG, Benn M, Schnohr P, Tybjaerg-Hansen A: Nonfasting triglycerides and risk of myocardial infarction, ischemic heart disease, and death in men and women. JAMA 2007;298:299-308. 


\section{Cellular Physiology Cell Physiol Biochem 2015;36:1767-1777 \begin{tabular}{l|l|l} 
DOI: 10.1159/000430149 & (C) 2015 S. Karger AG, Basel
\end{tabular}

10 Freiberg JJ, Tybjaerg-Hansen A, Jensen JS, Nordestgaard BG: Nonfasting triglycerides and risk of ischemic stroke in the general population. JAMA 2008;300:2142-2152.

- 11 Hegele RA, Ginsberg HN, Chapman MJ, Nordestgaard BG, Kuivenhoven JA, Averna M, Boren J, Bruckert E, Catapano AL, Descamps OS, Hovingh GK, Humphries SE, Kovanen PT, Masana L, Pajukanta P, Parhofer KG, Raal FJ, Ray KK, Santos RD, Stalenhoef AF, Stroes E, Taskinen MR, Tybjaerg-Hansen A, Watts GF, Wiklund $\mathrm{O}$ : The polygenic nature of hypertriglyceridaemia: implications for definition, diagnosis, and management. Lancet Diabetes Endocrinol 2014;2:655-666.

12 Gubensek J, Buturovic-Ponikvar J, Romozi K, Ponikvar R: Factors affecting outcome in acute hypertriglyceridemic pancreatitis treated with plasma exchange: an observational cohort study. PLoS One 2014;9:e102748.

13 Ling BL, Chiu CT, Lu HC, Lin JJ, Kuo CY, Chou FP: Short and long-term impact of lipectomy on expression profile of hepatic anabolic genes in rats: a high fat and high cholesterol diet-induced obese model. PLoS One 2014;9:e108717.

14 Moitra J, Mason MM, Olive M, Krylov D, Gavrilova O, Marcus-Samuels B, Feigenbaum L, Lee E, Aoyama T, Eckhaus M, Reitman ML, Vinson C: Life without white fat: a transgenic mouse. Genes Dev 1998;12:31683181.

15 Davidson NO, Shelness GS: Apolipoprotein B: mRNA editing, lipoprotein assembly, and presecretory degradation. Annu Rev Nutr 2000;20:169-193.

-16 Hussain MM, Shi J, Dreizen P: Microsomal triglyceride transfer protein and its role in apoB-lipoprotein assembly. J Lipid Res 2003;44:22-32.

17 Wetterau JR, Lin MC, Jamil H: Microsomal triglyceride transfer protein. Biochim Biophys Acta 1997;1345:136-150.

18 Raabe M, Veniant MM, Sullivan MA, Zlot CH, Bjorkegren J, Nielsen LB, Wong JS, Hamilton RL, Young SG: Analysis of the role of microsomal triglyceride transfer protein in the liver of tissue-specific knockout mice. J Clin Invest 1999;103:1287-1298.

19 Chang BH, Liao W, Li L, Nakamuta M, Mack D, Chan L: Liver-specific inactivation of the abetalipoproteinemia gene completely abrogates very low density lipoprotein/low density lipoprotein production in a viable conditional knockout mouse. J Biol Chem 1999;274:6051-6055.

20 Hooper AJ, van Bockxmeer FM, Burnett JR: Monogenic hypocholesterolaemic lipid disorders and apolipoprotein B metabolism. Crit Rev Clin Lab Sci 2005;42:515-545.

21 Hooper AJ, Burnett JR, Watts GF: Contemporary Aspects of the Biology and Therapeutic Regulation of the Microsomal Triglyceride Transfer Protein. Circ Res 2015;116:193-205.

22 Olofsson SO, Boren J: Apolipoprotein B: a clinically important apolipoprotein which assembles atherogenic lipoproteins and promotes the development of atherosclerosis. J Intern Med 2005;258:395-410.

23 Hayhurst GP, Lee YH, Lambert G, Ward JM, Gonzalez FJ: Hepatocyte nuclear factor 4alpha (nuclear receptor 2A1) is essential for maintenance of hepatic gene expression and lipid homeostasis. Mol Cell Biol 2001;21:1393-1403.

24 Krapivner S, Iglesias MJ, Silveira A, Tegner J, Bjorkegren J, Hamsten A, van't Hooft FM: DGAT1 participates in the effect of HNF4A on hepatic secretion of triglyceride-rich lipoproteins. Arterioscler Thromb Vasc Biol 2010;30:962-967.

-25 Yin L, Ma H, Ge X, Edwards PA, Zhang Y: Hepatic hepatocyte nuclear factor 4alpha is essential for maintaining triglyceride and cholesterol homeostasis. Arterioscler Thromb Vasc Biol 2011;31:328-336.

-26 Liang JJ, Oelkers P, Guo C, Chu PC, Dixon JL, Ginsberg HN, Sturley SL: Overexpression of human diacylglycerol acyltransferase 1, acyl-coa:cholesterol acyltransferase 1, or acyl-CoA:cholesterol acyltransferase 2 stimulates secretion of apolipoprotein B-containing lipoproteins in McA-RH7777 cells. J Biol Chem 2004;279:44938-44944.

27 Liu Y, Millar JS, Cromley DA, Graham M, Crooke R, Billheimer JT, Rader DJ: Knockdown of acylCoA:diacylglycerol acyltransferase 2 with antisense oligonucleotide reduces VLDL TG and ApoB secretion in mice. Biochim Biophys Acta 2008;1781:97-104.

28 Turyn J, Stojek M, Swierczynski J: Up-regulation of stearoyl-CoA desaturase 1 and elongase 6 genes expression in rat lipogenic tissues by chronic food restriction and chronic food restriction/refeeding. Mol Cell Biochem 2010;345:181-188.

29 Dettlaff-Pokora A, Sledzinski T, Swierczynski J: Neuropeptides after partial Lipectomy. J Appl Biomed 2015;13:105-12. 


\section{Cellular Physiology Cell Physiol Biochem 2015;36:1767-1777 \begin{tabular}{l|l|l} 
DOI: 10.1159/000430149 & (C) 2015 S. Karger AG, Basel
\end{tabular}

-30 Livak KJ, Schmittgen TD: Analysis of relative gene expression data using real-time quantitative PCR and the 2(-Delta Delta C(T)) Method. Methods 2001;25:402-408.

-31 Folch J, Lees M, Sloane Stanley GH: A simple method for the isolation and purification of total lipides from animal tissues. J Biol Chem 1957;226:497-509.

-32 Ramirez-Zacarias JL, Castro-Munozledo F, Kuri-Harcuch W: Quantitation of adipose conversion and triglycerides by staining intracytoplasmic lipids with Oil red O. Histochemistry 1992;97:493-497.

-33 Zelewski M, Swierczynski J: Comparative studies on lipogenic enzyme activities in brown adipose tissue and liver of the rat during starvation-refeeding transition and cold exposure. Comp Biochem Physiol B 1990;97:59-63.

-34 Cunningham BA, Moncur JT, Huntington JT, Kinlaw WB: "Spot 14" protein: a metabolic integrator in normal and neoplastic cells. Thyroid 1998;8:815-825.

-35 Foufelle F, Girard J, Ferre P: Regulation of lipogenic enzyme expression by glucose in liver and adipose tissue: a review of the potential cellular and molecular mechanisms. Adv Enzyme Regul 1996;36:199-226.

-36 Wendel AA, Cooper DE, Ilkayeva OR, Muoio DM, Coleman RA: Glycerol-3-phosphate acyltransferase (GPAT)1, but not GPAT4, incorporates newly synthesized fatty acids into triacylglycerol and diminishes fatty acid oxidation. J Biol Chem 2013;288:27299-27306.

37 Zammit VA: Hepatic triacylglycerol synthesis and secretion: DGAT2 as the link between glycaemia and triglyceridaemia. Biochem J 2013;451:1-12.

-38 Pramfalk C, Jiang ZY, Cai Q Hu H, Zhang SD, Han TQ Eriksson M, Parini P: HNF1alpha and SREBP2 are important regulators of NPC1L1 in human liver. J Lipid Res 2010;51:1354-1362.

- 39 Dai K, Hussain MM: NR2F1 disrupts synergistic activation of the MTTP gene transcription by HNF-4alpha and HNF-1alpha. J Lipid Res 2012;53:901-908.

-40 Hayhurst GP, Lee YH, Lambert G, Ward JM, Gonzalez FJ: Hepatocyte nuclear factor 4alpha (nuclear receptor 2A1) is essential for maintenance of hepatic gene expression and lipid homeostasis. Mol Cell Biol 2001;21:1393-1403.

-41 Yin L, Ma H, Ge X, Edwards PA, Zhang Y: Hepatic hepatocyte nuclear factor 4alpha is essential for maintaining triglyceride and cholesterol homeostasis. Arterioscler Thromb Vasc Biol 2011;31:328-336.

-42 Babeu JP, Boudreau F: Hepatocyte nuclear factor 4-alpha involvement in liver and intestinal inflammatory networks. World J Gastroenterol 2014;20:22-30.

43 Esposito K, Giugliano G, Scuderi N, Giugliano D: Role of adipokines in the obesity-inflammation relationship: the effect of fat removal. Plast Reconstr Surg 2006;118:1048-1057.

-44 Marfella R, Grella R, Rizzo MR, Barbieri M, Grella R, Ferraraccio F, Cacciapuoti F, Mazzarella G, Ferraro N, D'Andrea F, Paolisso G, Nicoletti G: Role of subcutaneous abdominal fat on cardiac function and proinflammatory cytokines in premenopausal obese women. Ann Plast Surg 2009;63:490-495.

45 Ryffel GU: Mutations in the human genes encoding the transcription factors of the hepatocyte nuclear factor (HNF)1 and HNF4 families: functional and pathological consequences. J Mol Endocrinol 2001;27:1129.

46 Zhong W, Mirkovitch J, Darnell JE, Jr.: Tissue-specific regulation of mouse hepatocyte nuclear factor 4 expression. Mol Cell Biol 1994;14:7276-7284.

47 Li P, Liu Y, Zhang Y, Long M, Guo Y, Wang Z, Li X, Zhang C, Li X, He J, Liu G: Effect of non-esterified fatty acids on fatty acid metabolism-related genes in calf hepatocytes cultured in vitro. Cell Physiol Biochem 2013;32:1509-1516.

48 Armendariz AD, Krauss RM: Hepatic nuclear factor 1-alpha: inflammation, genetics, and atherosclerosis. Curr Opin Lipidol 2009;20:106-111.

49 Deng Q Li X, Fu S, Yin L, Zhang Y, Wang T, Wang J, Liu L, Yuan X, Sun G, Wang Z, Liu G, Li X: SREBP-1c gene silencing can decrease lipid deposits in bovine hepatocytes cultured in vitro. Cell Physiol Biochem 2014;33:1568-1578.

-50 Shih DQ Dansky HM, Fleisher M, Assmann G, Fajans SS, Stoffel M: Genotype/phenotype relationships in HNF-4alpha/MODY1: haploinsufficiency is associated with reduced apolipoprotein (AII), apolipoprotein (CIII), lipoprotein(a), and triglyceride levels. Diabetes 2000;49:832-837.

-51 Ybarra J, Blanco-Vaca F, Fernandez S, Castellvi A, Bonet R, Palomer X, Ordonez-Llanos J, Trius A, Vila-Rovira R, Perez A: The effects of liposuction removal of subcutaneous abdominal fat on lipid metabolism are independent of insulin sensitivity in normal-overweight individuals. Obes Surg 2008;18:408-414. 